\title{
READING IN THE ELEMENTARY SCHOOLS OF INDIANAPOLIS
}

\author{
WILLIAM S. GRAY \\ School of Education, University of Chicago
}

INTRODUCTION

This report is based on one of a series of classroom investigations which have been undertaken during recent years by the supervisors and teachers of the public schools of Indianapolis. In each of these investigations the methods and materials used in the classrooms have been carefully scrutinized. Points of strength and weakness have been determined, and constructive suggestions have been offered which look toward improvement in the curriculum, in methods of teaching, and in classroom management. Reading was selected as the basis for this study because of its large importance in the elementary-school curriculum. In the lower grades ability to read is commonly adopted as the most important factor in determining promotions. In the upper grades ability to study content subjects intelligently is prerequisite to rapid progress. An investigation of reading assumes increased importance when the relation of reading ability to the various phases of school work is fully recognized.

The facts which are presented in this report were secured from various sources. During the early part of June, 1917, more than seven hundred teachers of Indianapolis prepared answers to nine questions relating to the aims, materials, and the methods which are employed in reading classes. The answers to several of these questions were tabulated, and the results are presented in tabular or graphical form in various 
sections of the report. A large quantity of valuable information was secured from the answers to the remaining questions. This material has been used frequently by way of illustration throughout the report.

Between September I3 and September 30, 1917, fifteen hundred reading tests were given to pupils in fifteen schools of Indianapolis. Gray's standardized oral-reading and silentreading tests were used. These tests, together with the directions for giving them and for scoring the results, are described in detail in "Studies of Elementary-School Reading through Standardized Tests," Vol. I, No. I, of the Supplementary Educational Monographs. The tests were given by thirty trained students of the Normal Training School of Indianapolis. In order that the tests might be given under comparable conditions in all the schools, supplementary sets of directions were provided for those who gave the tests and for the principals and teachers who co-operated. The tests were scored and the results checked by thirty normal-school students under the direction of the writer. The results of these tests supplied a body of objective data which was used to advantage in determining the results of reading instruction in Indianapolis.

The writers of this report spent seven days in Indianapolis between September 21 and September 28, 1917, securing as many data through observation and study as time permitted. In this connection two types of information were secured. In the first place, a careful study was made of all the basic and supplementary readers which are used in Indianapolis. In the second place, more than seventy recitations in reading were observed to secure added information concerning the methods which are employed by the teachers. Hundreds of classroom visits could be made with profit in a city as large as Indianapolis. The visits which were made, however, were sufficient in number to reveal the typical methods which are employed in 
reading classes. Evidence for this statement is found in the fact that the later visits revealed very few methods which had not been noted in earlier observations.

The report which follows is divided into three sections. The first presents a summary of those facts which were subject to quantitative determination. It includes the results of the tests and the summaries of the answers to several of the questions which were submitted to the teachers. The second section discusses the methods which are employed in teaching reading in Indianapolis, and outlines changes in classroom procedure wherever such changes are advisable. The third section describes the reading materials which are used, and outlines a number of fundamental principles which should guide teachers and supervisors in the selection of subject-matter for reading. Sections one and two were prepared by William S. Gray and will appear as the first four articles of this series. Section three was prepared by J. Franklin Bobbitt and will appear as the last two articles of this series.

Before passing on to a discussion of the results of the investigation the writers wish to express their appreciation of the cordial and effective co-operation which was given by the officers and teachers of Indianapolis. Superintendent E. U. Graff and Assistant Superintendents H. S. Gruver and Miss Laura Frazee placed every possible facility at the disposal of the investigators and gave generously of their time and labor. The classroom teachers presented recitations willingly under somewhat difficult conditions and gave a large amount of time to the careful preparation of answers to the questions which were submitted to them. The supervising principals made it possible to conduct the tests in the schools effectively. Miss Mary Pasho and the normal-school students merit special praise for the efficient and business-like way in which they assisted in giving the tests and in scoring the results. 


\section{AIMS OF READING INSTRUCTION}

Economy of time and effort in teaching any subject can be realized only when instruction is directed by well-defined aims. Furthermore, the successive stages through which a pupil passes in attaining these results must be clearly recognized. The latter prerequisite is highly essential in order that there may be concentration of attention in each grade on those phases of instruction which are most appropriate. In order to determine what are the fundamental aims of teaching reading in the elementary schools of Indianapolis, and in order to determine the extent to which the teachers of each grade endeavor to aid in the accomplishment of these results, the following questions were submitted to the teachers: (I)"What are the most desirable results or outcomes of the teaching of of reading in the elementary school?" (2) "How does reading instruction in your grade contribute to the results outlined above?"

The answers to these questions were tabulated for each grade. After the aims had been tabulated under a large number of different headings they were combined into thirteen fairly distinct groups as given in Table I. The number of times that each aim was mentioned was determined, and this number was then expressed as a percentage of the total number of teachers replying for a given grade. The results for each grade and for all eight grades combined are given for each question in Table I. The results for question I are given under $a$, and the results for question 2 are given under $b$.

Table I reveals marked similarity between the general aims of reading and the specific contributions which each grade makes to reading. There are several noteworthy exceptions to this general correspondence in aims. For illustration, "appreciation of literature" receives more emphasis as a general aim of reading in the elementary school than as a specific 


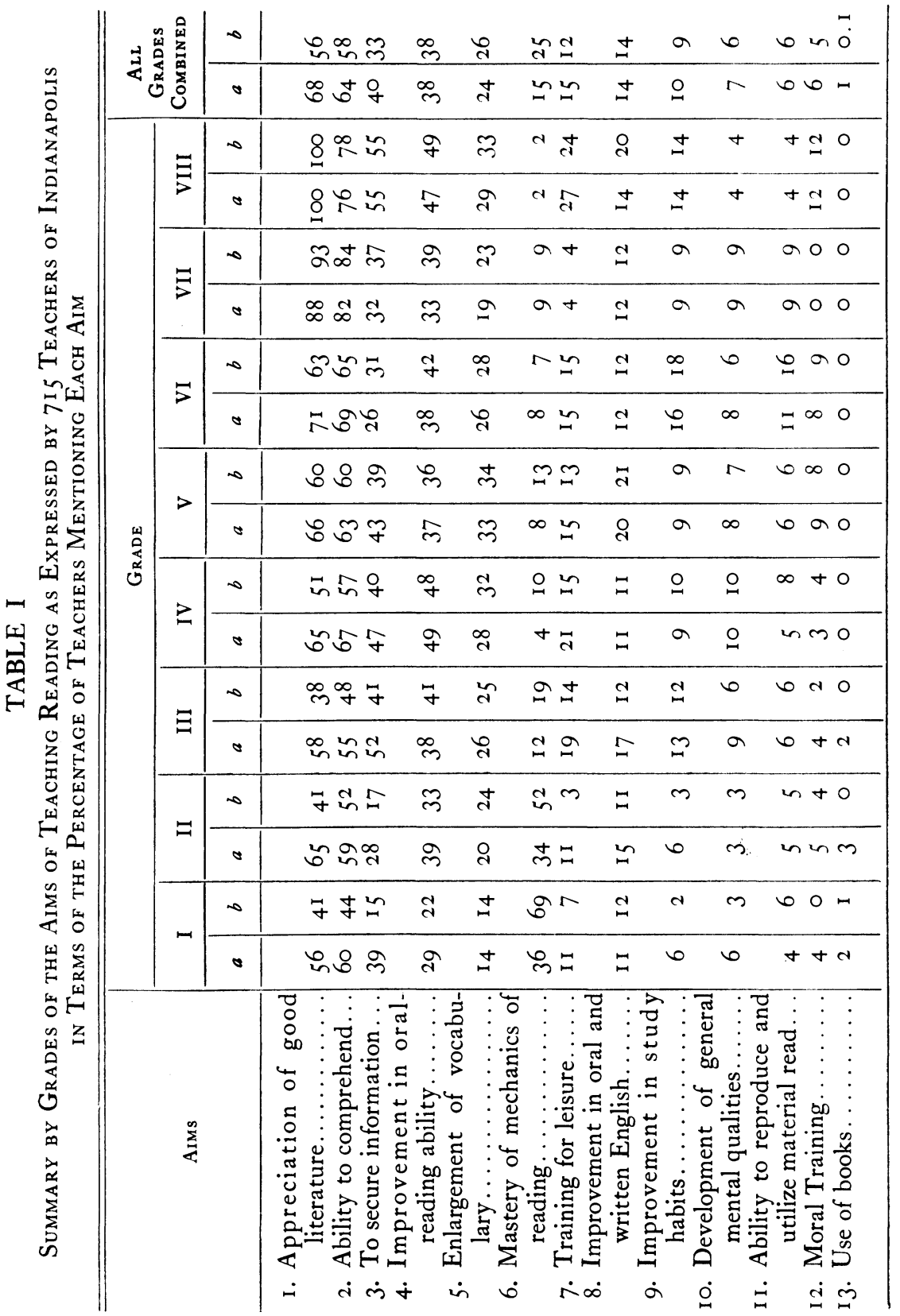

This content downloaded from 076.000.130.239 on February 21, 2018 16:45:26 PM All use subject to University of Chicago Press Terms and Conditions (http://www.journals.uchicago.edu/t-and- 
aim for either of the first four grades. Similar statements can be made in regard to "ability to comprehend" and "to secure information." "The mastery of mechanics," on the other hand, is given greater emphasis as a specific aim for the lower grades than as a general aim of reading instruction.

In order to bring out more clearly certain contrasts, the facts of Table I are presented graphically in Diagram I. The
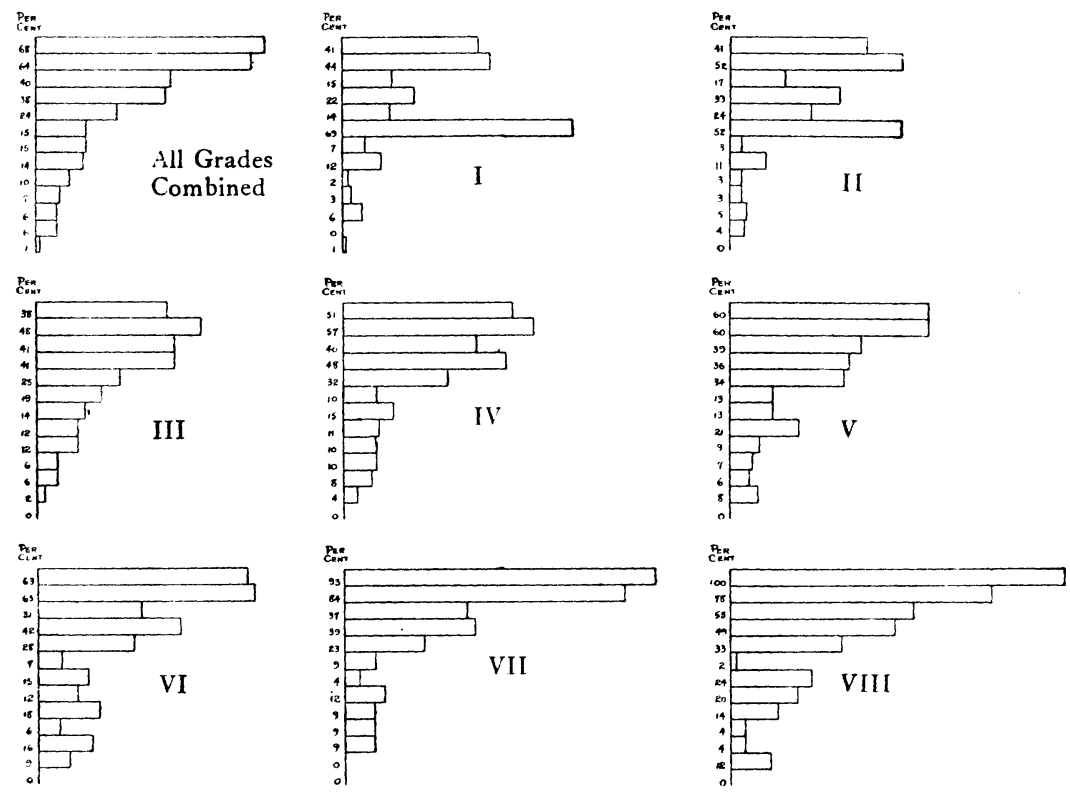

DiAgram I. Summary by grades of the aims of teaching reading as expressed by 715 teachers of Indianapolis, Indiana

results for "all grades combined" are based on question I, and the results for each grade are based on question 2. In each figure of Diagram I the thirteen aims appear in the same order in which they are listed in the left-hand column of Table I. The diagram brings out clearly the fact that the aims as stated for each grade bear about the same relative importance to each other as they do in the diagram for "all grades combined." 
The diagrams for the first, second, and sixth grades are the most noteworthy exceptions.

Diagram 2 presents the facts of Diagram I in a different form to bring out the relative importance of each of the thirteen aims in the various grades. The diagram reveals the
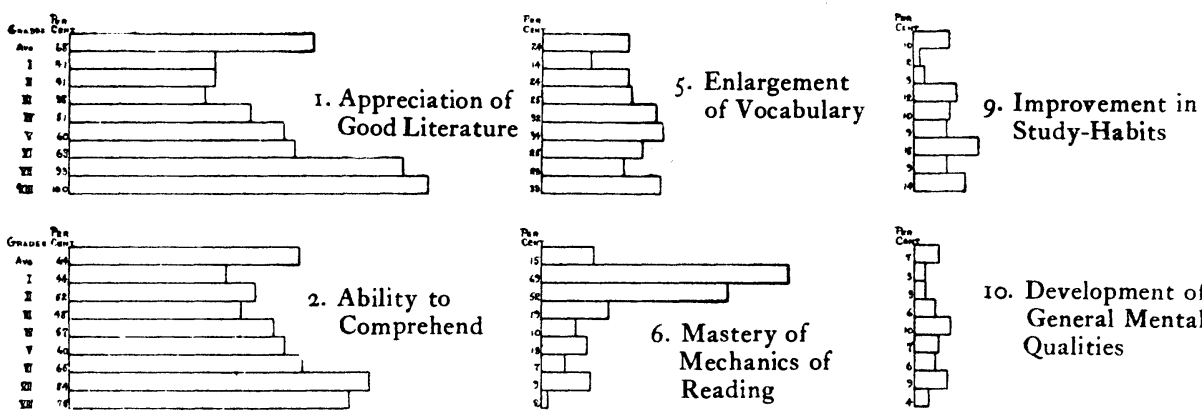

10. Development of General Mental Qualities

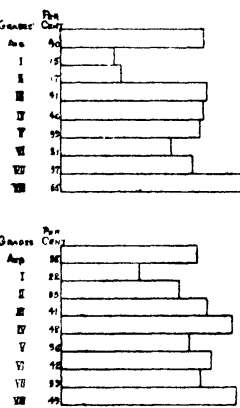

3. Torsecure Information

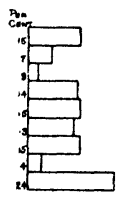

7. Training for Leisure

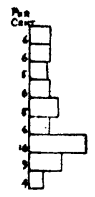

II. Ability to Reproduce and Utilize Material Read

4. Improvement in Oral-Reading Ability

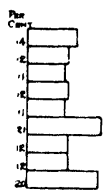

8. Improvement in Oral and Written English

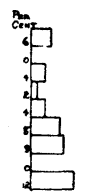

12. Moral

Training

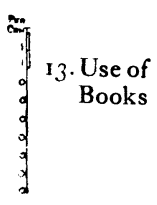

DIAGRAM 2. The relative importance of 13 aims of teaching reading in the various grades of Indianapolis

following important facts: (I) "Appreciation of good literature" and "ability to comprehend" are important aims throughout the grades, receiving less emphasis in the lower grades and more emphasis in the upper grades. (2) "To secure information" is an aim of minor importance in the first two grades. The distinct increase in its importance in the third grade is noteworthy. The apparent decrease in the importance of information during the intermediate grades is 
difficult to explain. (3) The increasing importance attached to "improvement in oral-reading ability" in the first four grades and the relatively large prominence given to it in the upper grades are characteristic of the traditional point of view. The appropriateness of this aim will be commented on in greater detail in later sections. (4) The decreasing importance attached to the "mastery of the mechanics of reading" in the successive grades is commendable and in harmony with natural expectation. (5) Without commenting in detail on each figure of the diagram, attention is called to the small amount of importance attached to "improvement in study habits" and to training in the "use of books." Inasmuch as these phases of reading ability are factors of the greatest importance in the development of effective study-habits, it is evident that more emphasis should be given to them than is indicated by the teachers in their statements of aims.

The reports submitted by the teachers varied widely in the clearness and the definiteness with which the aims of reading were discussed. Some statements were very vague and general and indicated that the teacher had an inadequate view of the specific problems involved in reading instruction. One fifthgrade teacher replied to the questions on aims as follows:

2uestion 1. - What do you consider are the most desirable outcomes or results of teaching reading in the elementary school?

Reply.-To interpret the printed page and to give its meaning to another.

2uestion 2.- How does reading instruction in your grade contribute to the results outlined above?

Reply.-I don't know.

A seventh-grade teacher made the following replies to the questions:

1.- To promote culture. To broaden the view.

2.- Seems to accomplish the above results.

It is evident that these teachers were thinking of the aims of reading only in very general terms. They gave no evidence 
in their replies of a clear conception of the specific problems which confront their pupils. Many teachers, on the other hand, were definite and specific in their statements. Their replies indicated a clear realization of the problems which confront them and of the methods which are appropriate for securing effective results. The replies of a seventh-grade teacher are presented below. The report merits very favorable mention because of the clearness with which the teacher saw the relation between means and ends. It represents the type of intelligent mastery of the problem which every teacher of Indianapolis should have if the city as a whole is to secure the most effective results from the time and energy which it devotes to reading instruction.

2uestion I. -What do you consider are the most desirable outcomes or results of teaching reading in the elementary school.

Reply.-I. Ability to get thought from a printed page.

2. Speed in reading.

3. Formation of dictionary habit.

4. Increased vocabulary.

5. Interest in current news.

6. Formation of library habit.

7. Creation of standards of taste.

8. Appreciation of notable pieces of literature.

9. Interest in subject read.

2uestion 2.- How does reading instruction in your grade contribute to the results outlined above?

Reply.-I. Systematic training in silent reading develops ability to master the thought.

2. This, too, when made a competitive class exercise, increases the speed of reading.

3. The use of the dictionary is encouraged in the preparation of reading lessons amd also in the silent-reading class exercise when speed is not an objective.

4. Fitting the right meanings of words to their uses in sentences increases a pupil's vocabulary. Extensive use of these words is encouraged in spoken and written composition. 
5. The interest of the class is aroused in matters of general interest, such as gardening, food economy, the Liberty Loan, or Red Cross work, to such an extent that clippings from daily papers are brought and read, or passed about, or posted on the bulletin board.

6. During a part of the term the class has met once a week in the library and the pupils have taken out and returned the books which they have selected to read. These are recommended by one to another, and sometimes a report is given by one pupil to the other members of the class.

7. The encouragement of a better class of fiction really does implant in the child a feeling for better books.

8. Some selections are read merely for appreciation, sometimes by the teacher in morning exercises, sometimes recited by a pupil, or again memorized by a class.

9. The interest aroused by reading such a book as Burroughs' Birds and Bees is of great importance, and the influence of extensive reading of this type is far-reaching. A boy wants to explain how he made his canoe, a girl produces a birch-bark booklet from Vermont, and so the experiences multiply. This interest may take the form of a problem or question. A class discussion ensues, or an extended investigation follows.

The study of aims can be summarized as follows: (I) The aims for each grade are not clearly differentiated from the general aims of teaching reading. While it is true that each grade contributes directly to the realization of several of the general aims of reading instruction, nevertheless, it is equally true that certain specific aims, such as the mastery of mechanics of reading, the development of fluency in oral reading, the improvement of rate in silent reading, etc., should be emphasized at definite periods in the development of reading ability, if the most valuable results are to be realized. Inasmuch as the aims of reading instruction are conceived very largely by many teachers of Indianapolis in terms of general outcomes or results, there is danger that certain phases will not be emphasized sufficiently when emphasis is most appropriate.

(2) The 
large importance attached to comprehension throughout the grades and the restriction of emphasis on mechanics of reading to the lower grades are commendable tendencies. (3) The large importance attached to appreciation of literature in the first and second grades before the pupil has learned the technique of reading a simple statement of fact, the large amount of emphasis given to oral reading throughout the grades, and the slight importance attached to improvement in study-habits and to training in the use of books represent tendencies which are questionable. (4) There is wide variation among teachers in regard to the definiteness with which they outline their reading problems and in regard to the clearness with which they perceive the relation of specific methods to progress in the development of reading ability. These facts justify the recommendation that steps be taken at once to instruct teachers in regard to the most important points for emphasis in each grade. Suggestions will be presented in later sections which can be used in this connection.

\section{TIME ALLOTMENT}

The amount of time given to instruction in any subject is a matter of importance. This is particularly true in the case of reading in the lower grades where the pupils are more or less dependent on direct help from the teacher. The number of hours given to reading in each grade in Indianapolis and and in Cleveland, together with the average number of hours for fifty cities, is presented in Table II.

Table II reveals two significant facts. In the first place, Indianapolis gives less time to reading in each grade than is true in the case of Cleveland or the average for fifty cities. In the second place, Indianapolis gives only one-half as many hours each year to reading as the average for fifty cities and only one-third as many hours as Cleveland. Any comparison of results in reading for Indianapolis with results for other 
cities should take into account the surprisingly small amount of time given by Indianapolis to instruction in reading. As will be brought out later, Indianapolis ranks low in reading accomplishment and is, therefore, confronted with the problem of increasing the accomplishment of its pupils in reading. Inasmuch as Indianapolis devotes a relatively small amount of

TABLE II

Hours Given to Reading Per Year

\begin{tabular}{|c|c|c|c|c|c|c|c|c|c|}
\hline \multirow{2}{*}{ City } & \multicolumn{8}{|c|}{ Grades } & \multirow{2}{*}{ Total } \\
\hline & I & II & III & IV & V & VI & VII & VIII & \\
\hline $\begin{array}{l}\text { Average for fifty cities. } \\
\text { Cleveland........... } \\
\text { Indianapolis } \ldots \ldots \ldots \ldots\end{array}$ & $\begin{array}{l}266 \\
317 \\
165\end{array}$ & $\begin{array}{l}235 \\
317 \\
105\end{array}$ & $\begin{array}{l}188 \\
279 \\
120\end{array}$ & $\begin{array}{r}153 \\
196 \\
75\end{array}$ & $\begin{array}{r}126 \\
161 \\
60\end{array}$ & $\begin{array}{r}117 \\
136 \\
60\end{array}$ & $\begin{array}{r}98 \\
152 \\
36\end{array}$ & $\begin{array}{r}97 \\
152 \\
36\end{array}$ & $\begin{array}{r}1,280 \\
1,710 \\
657\end{array}$ \\
\hline
\end{tabular}

time to reading instruction, a partial solution of the problem consists in making adjustments which will give more time to this subject.

Increased time for reading can be secured in Indianapolis by making the following changes: (I) The school day, which now includes four and one-fourth working hours, could be increased to five hours in harmony with current practice in many progressive school systems. (2) The half-day sessions now provided for IB pupils could be increased to whole-day sessions. (3) The three-class program now prevailing in the first three grades of most schools could be reduced to a twoclass basis. This suggestion presupposes, of course, an increase in the number of teachers and classrooms available for these grades. (4) Time now devoted to some subjects of less importance than reading could be used as reading periods. 


\section{PROPORTION OF TIME GIVEN TO ORAL READING AND TO SILENT READING}

Recent investigations in elementary-school subjects reveal the fact that the results which a school secures in a given subject depend not only on the total amount of time given to the subject, but also on the way in which the available time is utilized. The following discussion relates to the proportion of time given to oral reading and to silent reading respectively in the various grades of Indianapolis. In order to secure detailed information on this point the following questions were submitted to the teachers: (I) "What percentage of the time set aside for reading in your grade is given to oral-reading instruction?" (2) "What percentage of the time set aside for reading in your grade is given to silent-reading instruction?"

The answers to these questions were tabulated and the results are presented in Table III. The left-hand column gives various units into which the answers given by the teachers were grouped. For illustration: The answers of all teachers

\section{TABLE III}

Percentages of Reading Time Given to Oral-Reading Instruction and to Silent-Reading Instruction in 702 Classrooms

OF INDIANAPOLIS

\begin{tabular}{|c|c|c|c|c|c|c|c|c|c|c|c|c|c|c|c|c|}
\hline \multirow{2}{*}{$\begin{array}{c}\text { Grades... } \\
\begin{array}{l}\text { Per cent } \\
\text { of Time }\end{array}\end{array}$} & \multicolumn{2}{|c|}{ I } & \multicolumn{2}{|c|}{ II } & \multicolumn{2}{|c|}{ III } & \multicolumn{2}{|c|}{ IV } & \multicolumn{2}{|c|}{ V } & \multicolumn{2}{|c|}{ VI } & \multicolumn{2}{|c|}{ VII } & \multicolumn{2}{|c|}{ VIII } \\
\hline & 0 & $\mathbf{S}$ & O & $\mathbf{S}$ & $\mathrm{O}$ & $S$ & 0 & $\mathbf{S}$ & $\mathrm{O}$ & $\mathrm{S}$ & 0 & $S$ & 0 & $\mathrm{~S}$ & 0 & $\mathrm{~S}$ \\
\hline o.. & & 7 & & I & & I & & & & 2 & & 5 & 4 & 4 & 2 & \\
\hline $1-10$. & $\ldots$ & 15 & & 6 & . & 4 & 2 & & 5 & 8 & & 3 & 6 & 7 & I 4 & \\
\hline I I -20. & 2 & 12 & 2 & I 5 & 4 & 4 & 4 & 6 & 9 & 12 & 6 & I I & $\cdots$ & 14 & 6 & \\
\hline $21-30$. & 3 & 27 & 5 & 19 & 3 & 14 & 5 & 13 & 8 & I0 & 15 & I I & 4 & 10 & 15 & \\
\hline $3 I-40$ & 7 & 15 & II & 20 & 22 & 26 & 25 & 27 & I I & 35 & 17 & 20 & 12 & 22 & 16 & \\
\hline $4 I-50 \ldots$ & I I & II & 27 & 22 & 33 & 27 & 27 & 25 & 15 & 14 & 25 & 27 & 30 & 26 & 18 & 22 \\
\hline & $I$ & I & 14 & 9 & 12 & 7 & 22 & 14 & 34 & 5 & II & I0 & I I & 2 & 8 & \\
\hline $6 \mathbf{I}-70$ & 16 & I & 15 & 8 & $I_{4}$ & 9 & 4 & Io & 2 & 3 & 8 & 6 & I 2 & 4 & 2 & \\
\hline $71-80$. & 40 & I & 19 & $\cdots$ & 9 & 4 & I I & 4 & 12 & 8 & I 5 & 7 & 12 & 5 & I 3 & 15 \\
\hline & 15 & & 6 & & 2 & I & & & 3 & & 2 & & 4 & 2 & 2 & \\
\hline $91-100 \ldots$ & 5 & $\ldots$ & I & $\ldots$ & I & $\ldots$ & .. & . & I & $\ldots$ & $\mathbf{I}$ & $\ldots$ & 5 & 2 & 4 & \\
\hline & & IO & & & & 3 & & I & $\ldots$ & 3 & & & & 2 & & \\
\hline
\end{tabular}


who reported that they gave no time to oral reading were grouped together; the answers of all who gave from I to Io per cent of the reading time to instruction in oral reading were grouped together, etc. Inasmuch as some teachers did not answer definitely in the case of silent reading, it was necessary to adopt an "indefinite" unit. The entries in the table give the percentages of teachers devoting various percentages of the reading time to oral-reading and to silent-reading instruction. In the case of each grade the entries under "O" refer to the percentages of teachers devoting various percentages of time to oral-reading instruction, and the entries under "S" refer to the percentages of teachers devoting various percentages of time to silent-reading instruction. In the first grade, for illustration, 2 per cent of the teachers gave from i I to 20 per cent of the reading time to oral reading; 3 per cent of the teachers gave from 21 to 30 per cent of the reading time to oral reading, etc.

Table III reveals the fact that there is very wide variation in practice in regard to the proportion of time given to oral reading and to silent reading. In Grade VII, for illustration, some teachers give all of the time to silent-reading instruction and some give all of the time to oral-reading instruction. On the other hand, there are teachers in the same grade who give no time to oral reading, and others who give no time to silent reading. Such wide variations in practice must be interpreted to mean equally wide variations in the kind of results for which the teachers are striving. Additional facts are brought out by Diagram 3 and Diagram 4, each of which is based on the data presented in Table III.

Diagram 3 shows the percentages of teachers in each grade who devote various percentages of the reading time to oralreading instruction. The wide variation in practice mentioned in the preceding paragraph is illustrated clearly in the figure for each grade. The diagram for the first grade shows that 


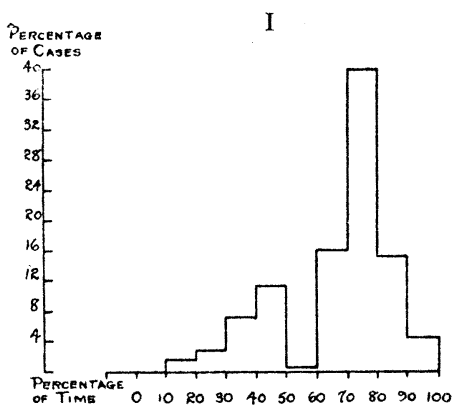

II

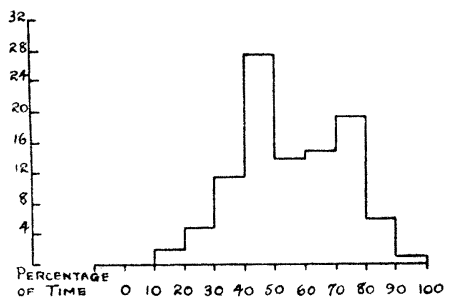

III

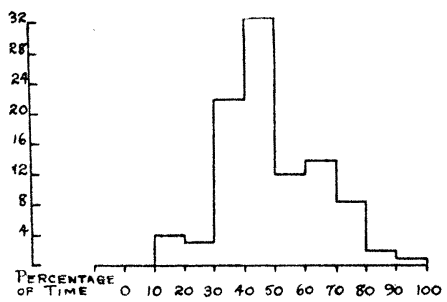

IV

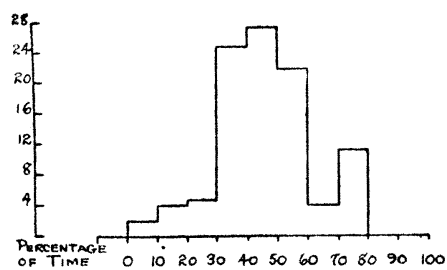

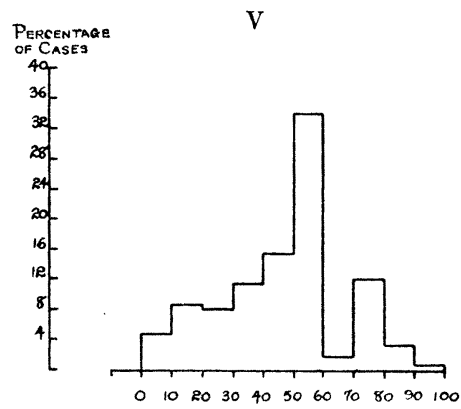

VI

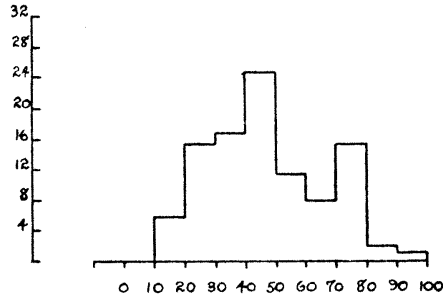

VII

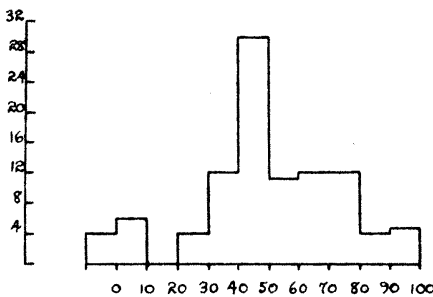

VIII

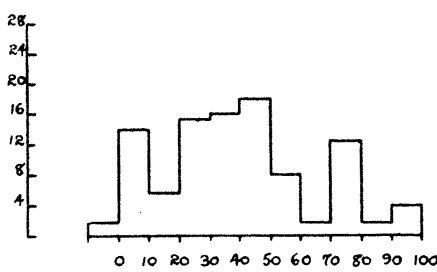

Diagram 3. Percentage of time devoted to oral reading in 702 classrooms of Indianapolis

This content downloaded from 076.000.130.239 on February 21, 2018 16:45:26 PM All use subject to University of Chicago Press Terms and Conditions (http://www.journals.uchicago.edu/t-and- 
the majority of the teachers give from 70 to 90 per cent of the reading time to oral-reading instruction. It is doubtless appropriate to devote a very large percentage of the reading time to oral-reading instruction during that period when the pupil is mastering the fundamentals of the reading process. The diagrams for the second, third, and fourth grades show a gradual decrease in the percentage of time devoted to oralreading instruction, and a marked tendency toward uniformity of practice which reaches a climax in the fourth grade. The diagrams for the upper grades present two marked tendencies. In the first place, there is a marked tendency toward wide variation in practice which reaches a climax in the eighth grade. This suggests the possibility that the aims of reading instruction have not been as clearly or as definitely defined in the upper grades as in the lower grades. In the second place a larger percentage of the reading time is given to oral-reading instruction than is true for the fourth grade. When one compares the relative importance of oral reading and silent reading as they relate to success in school and in the various pursuits of life, one is forced to question the advisability of giving so large a proportion of the reading time in the upper grades to oral-reading instruction.

Diagram 4 presents the facts in regard to the proportion of the reading time which is devoted to silent-reading instruction. The diagrams for the first four grades show a gradual increase in the percentage of time devoted to silent-reading instruction, and a marked tendency toward uniformity of practice which reaches a climax in the fourth grade. The diagrams for the four upper grades show two marked tendencies. In the first place, there is a distinct tendency toward wide variation in practice which reaches a climax in the eighth grade. In the second place, a larger percentage of the teachers of these grades devote less time to silent reading than is true for the fourth grade. In view of the large importance of 
352

THE ELEMENTARY SCHOOL JOURNAL

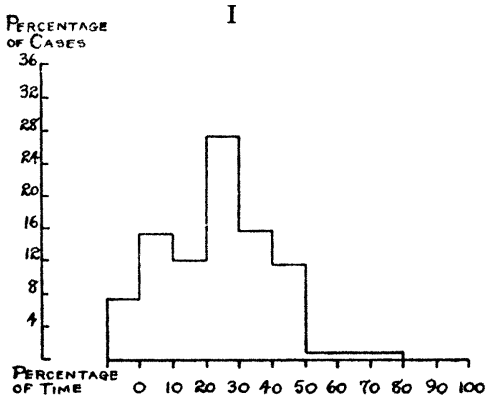

II

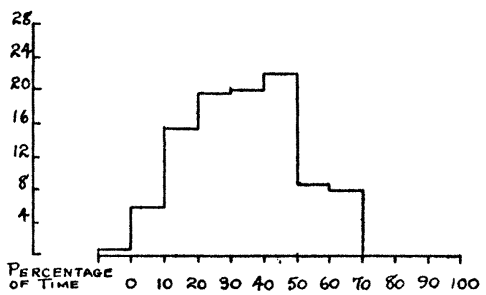

III

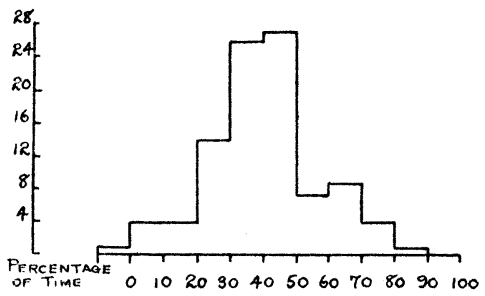

IV

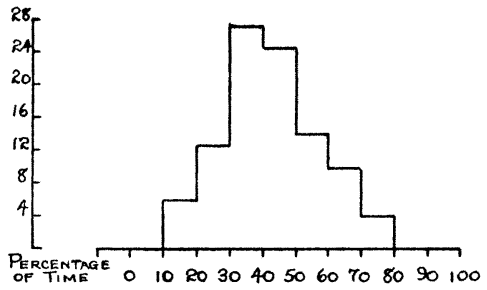

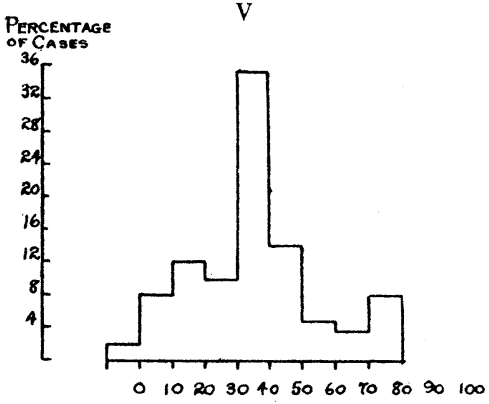

VI

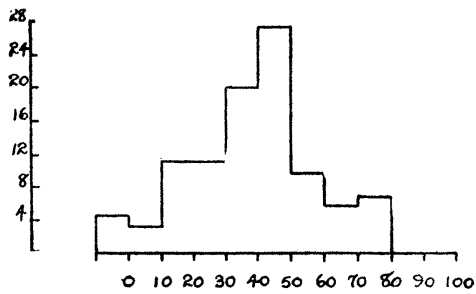

VII

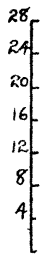

VIII

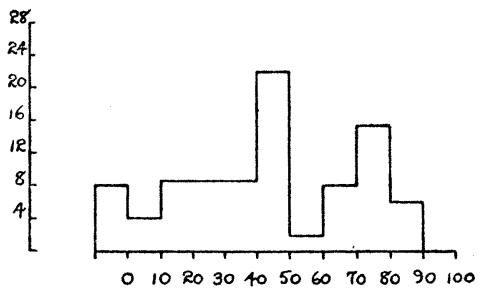

Diagram 4. Percentage of time devoted to silent reading in 702 classrooms of Indianapolis

This content downloaded from 076.000.130.239 on February 21, 2018 16:45:26 PM All use subject to University of Chicago Press Terms and Conditions (http://www.journals.uchicago.edu/t-and- 
silent reading both in and out of school, the tendency toward increased emphasis on silent reading which was begun in the lower grades should have been continued in the intermediate and grammar grades.

The quantitative data in regard to the time given to reading in Indianapolis may be summarized as follows: (I) Indianapolis devotes a relatively small amount of time to reading instruction. There is evident need for increasing the amount of time given to reading in each grade. (2) There is very wide variation in the practice of teachers, particularly in the grades above the third, in regard to the amount of time given to oral reading and to silent reading. This marked variation gives additional emphasis to the need for a clearer definition of the most desirable results of reading instruction in these grades. (3) There is a strong tendency in the lower grades toward a decrease in the percentage of time devoted to oralreading instruction and an increase in the percentage of time devoted to silent-reading instruction. This tendency reaches a climax in the fourth grade. Beyond the fourth grade there is a tendency in some schools to increase the emphasis on oral reading and to decrease the emphasis on silent reading. This tendency toward greater emphasis on oral-reading instruction in the intermediate and grammar grades is questionable in view of the relatively greater importance and use of silent reading. 